\title{
UN PROGRAMA PARA LA SOCIOLOGÍA DE LA FILOSOFÍA
}

\section{APROGRAM FOR THE SOCIOLOGY OF PHILOSOPHY}

\author{
José Luis Moreno Pestaña joseluis.moreno@uca.es \\ Universidad de Cádiz. España
}

\section{RESUMEN}

En este artículo se presentan, en primer lugar, los vínculos posibles entre la filosofía y las ciencias sociales, a partir de, por un lado, los modos de autocomprensión del trabajo filosófico y, por otro, los efectos de los recursos filosóficos en la vocación de científico social. Posteriormente, se analizan los modos de protección de la filosofía frente a la sociología. En tercer lugar, se estudia cómo la sociología permite mejorar la reflexividad filosófica a partir de una descripción densa de las jerarquías que organizan el espacio filosófico: la sociología de la filosofía aparece entonces no como un ataque a la filosofía sino como un incremento de la capacidad autocrítica del trabajo filosófico. En cuarto lugar y, para acabar, se exploran las redes filosóficas como criterio de comprensión de procesos de creatividad intelectual. El trabajo presenta en cada uno de sus momentos ejemplos concretos derivados fundamentalmente de la historia del pensamiento español y francés del siglo XX.

\section{Palabras Clave}

Epistemología de las ciencias sociales; Historia del pensamiento contemporáneo; Redes de intelectuales.

\begin{abstract}
In this paper I present, in the first place, the possible links between philosophy and social science, from, on the one hand, the autounderstanding ways of the philosophical work, and in the second hand, philosophical resources effects on the social scientific vocation. Subsequently, I analyse the philosophical protection against sociology. In third place, I study how sociology permits to improve the philosophical reflexivity from a thick description of the hierarchy that organizes the philosophical field: so, sociology of philosophy appears, not as an attack to philosophy, but as an increase of the philosophical work critical capacities. In fourth place, to finish, I explore philosophical nets as understanding criterion of intellectual creativity. The paper presents specific examples which came basically from the history of Spanish and French thought in the XX century.
\end{abstract}

\section{KEYWORDS}

Epistemology of Social Sciences; History of Contemporary Thought; Intellectualls' Nets. 


\section{INTRODUCCIÓN ${ }^{1}$}

¿Qué hace actual a un filósofo y a una filosofía? ¿Por qué nos interesamos por él? ¿Qué proporciona en sus textos valor intelectual y placer estético, capacidad de orientación moral y política? La respuesta de una cierta concepción de la filosofía consiste en remitirse a la obra consagrada y separarla de todo cuanto no sea filosófico en la vida de su productor. Cantidades ingentes de libros, artículos y conferencias de filosofía se consideran filosóficas porque evitan hacer cualquier otra cosa que "leer" una obra; algunos la completan con la comparación con "otra" obra y, algunos menos, con la aplicación de esa obra a una "realidad". Este modelo es el que se inculca en la mayoría de las Facultades de filosofía españolas. Los defensores del mismo lo mantienen blandiendo frente a la alternativa que aquí se defiende una serie de pecados filosóficos acabados en "-ismo": historicismo, sociologismo, psicologismo..., etc.

Ese modelo pervive en autores tanto de la tradición llamada continental como de la tradición analítica; por lo demás, en ambas tradiciones se encuentran autores que disienten del mismo. Dicho modelo, en su forma pura (la que el autor de este texto adquirió durante su formación como filósofo), presume que resulta fácil de discernir lo que es filosófico de lo que no lo es en la producción de un discurso; se cree, además, que lo de "fuera" no influye en lo de "dentro". Los supuestos de esta perspectiva son dos: existe una frontera y esta frontera es impermeable.

Sea más o menos compartida, semejante visión de la filosofía no es la única. En mi argumentación recogeré aportaciones de filósofos que convienen perfectamente a la tarea sociológica que me planteo. La acepción que llamaré canónica de la filosofía se encuentra impulsada por el trabajo, más o menos disciplinado y constante, de una fracción del gremio filosófico sobre sus propias fronteras. El hecho de que en raras ocasiones sea defendida explícitamente muestra que su poder de convicción reposa más en las certidumbres de la socialización gremial que en la confrontación argumentativa.

En este artículo, en primer lugar, precisaré brevemente el modelo mediante un ejemplo con el que se pretende separar la filosofía de su exterior -en el caso, como se verá, la profecía- por medio de una construcción de un tipo ideal. Posteriormente, explicaré mi concepción de las relaciones entre filosofía y sociología a la hora de realizar una sociología de los intelectuales. Seguidamente, en dos apartados, señalaré los conflictos existentes, primero, para definir o no qué es filosofía y, después, para ver qué trayectoria filosófica es más o menos brillante. El apartado sobre la creatividad explicará con ejemplos las condiciones sociales de posibilidad de la productividad filosófica. Los dos últimos apartados analizarán la dialéctica entre el diálogo con redes intelectuales productivas y la reputación de un filósofo. Buena parte

\footnotetext{
${ }^{1}$ Texto escrito en el marco del proyecto de I+D FFI2010-15196.
} 
de los casos analizados se apoyan, además de en una discusión de la bibliografía al respecto, en mis dos grandes centros de interés: el análisis del campo filosófico francés y mi presente estudio sobre el campo filosófico español después de la guerra civil de 1936.

\section{LOS MÚLTIPLES SENTIDOS DE LA FILOSOFÍA}

\section{La filosofía no es sólo argumentación intelectual}

En el capítulo VII del Tratado teológico-político, Spinoza propone un modelo de lectura para los libros sagrados. Para comprenderlos debe describirse la vida del autor de cada libro, los objetivos que estos se planteaban y en qué lengua y en qué universo simbólico se escribió el libro; por lo demás, debe explicarse quién decidió convertirlos en un corpus único e incluirlo dentro del canon de los libros sagrados. Para el análisis de la profecía, Spinoza nos invita a un conjunto claro de operaciones de investigación, sin duda productivas para la sociología de la filosofía: estudio de la experiencia social de los productores, de los universos simbólicos en los que debieron expresarse, de los efectos de la conversión de un producto cultural en un bien simbólico de un campo intelectual.

Puede pensarse que el modelo de análisis de las profecías no resulta apropiado para analizar un campo como la filosofía, al fin y al cabo, producto del ejercicio argumentativo. $Y$, en efecto, el mismo Spinoza confronta en múltiples ocasiones la filosofía con la profecía. La filosofía se apoya en la razón -en principio, accesible a todos-y, por ello, puede prescindir de los prestigios carismáticos del profeta: aquel que escucha a un filósofo se convierte en filósofo porque adquiere sus capacidades racionales, aclara Spinoza, pero el que escucha a un profeta no se convierte en profeta; debe otorgarle autoridad, porque sin ella no tiene manera alguna de comprobar la verdad que le muestra: esa autoridad es una condición para que el agente realice la verdad predicha (Spinoza 1965: 30). ¿El filósofo sería depositario de un discurso ajeno a su contexto de formación, susceptible de ser comprendido única y exclusivamente en sus encadenamientos conceptuales internos? Sí, si el discurso filosófico fuera semejante al que Spinoza atribuye a Euclides "que no escribió sino cosas muy simples y sumamente inteligibles, [y] cualquiera lo puede explicar en cualquier lengua. Puesto que para captar su pensamiento y estar ciertos de su verdadero sentido, no es necesario tener un conocimiento completo de la lengua en la que escribió, sino muy ordinario y casi infantil; no es necesario conocer la vida ni las aficiones ni las costumbres del autor; ni en qué lengua escribió, para quién y cuándo, ni los avatares del libro ni sus diversas lecturas, ni cómo ni quiénes aconsejaron aceptarlo" (Spinoza 1965:111).

Dejemos de lado la discusión de si semejante caracterización de Euclides es correcta. Interesa en este momento la caracterización de dos modelos de lectura que propone Spinoza: una lectura interna para los textos matemáticos - que identifica con la filosofía-y una lectura externa para textos compuestos por, en primer lugar, las propiedades subjetivas 
de su autor y sus objetivos vitales, en segundo lugar, los significados complejos de una lengua y, en tercer lugar, textos cuya posteridad procede del trabajo que un grupo de receptores han realizado sobre ellos. Resulta sencillo mostrar cómo los textos filosóficos ${ }^{2}$ entran plenamente dentro de dicha clase de textos y muy raramente entre aquella que agruparía, si siguiéramos a Spinoza, los trabajos de Euclides. De hecho, más que de una diferencia radical entre la filosofía y las prácticas religiosas y/o proféticas, cabría hablar de un continuo de prácticas discursivas que incluyen conocimientos (en grado diverso: se supone que de infinita mejor calidad los textos filosóficos), un mensaje de salvación (individual y/o colectivo) $)^{3}$ y un conjunto de prácticas de modificación de sí mismo y de elaboración de la propia subjetividad. Qué sea o no religioso y qué sea o no filosófico es una cuestión históricamente variable y sometida a conflictos de demarcación.

Por un lado, filosofía y religión no se repelen y a menudo proceden de un tronco común. Los análisis de Randall Collins (2000:205-208) sobre el desarrollo de la filosofía budista en la India son suficientemente significativos al respecto y su teoría de los rituales de interacción filosóficos proporciona argumentos para no proceder a una separación tajante entre prácticas filosóficas y prácticas religiosas. Los procesos de reflexividad que se desencadenan en las grandes religiones han sido una fuente tradicional de producción filosófica. Además, las prácticas de consagración de objetos rituales (valor sapiencial otorgado a ciertos textos, repetición constante de ciertas fórmulas, culto celebrado a ciertos intelectuales del panteón, condena violenta de los impostores 0 herejes) en la filosofía no son de naturaleza esencialmente diferente a las prácticas religiosas.

Esta cuestión exige reconstrucciones coyunturales precisas y su comparación, si se quieren producir generalizaciones que sean algo más que prejuicios. La sociología histórica de las escuelas helenísticas realizada por Michel Foucault (2001:111-112) ofrece una pista interesante para relacionar el origen social con el modo de practicar la filosofía y/o la religión. Las escuelas helenísticas generalizaron las prácticas de reflexión sobre la propia vida que el mundo ateniense reservaba a una cierta elite. Evidentemente, existía un umbral económico y cultural por debajo del cual era sumamente improbable

\footnotetext{
${ }^{2}$ Aunque no solo estos. La diferencia entre los textos de ciencias humanas, los literarios y los filosóficos es un asunto conflictivo. Llamar filosófico a un texto puede servir para enaltecerlo (cuando se dice: "La montaña mágica es una gran obra de filosofía moral") o denigrarlo (cuando se dice: "Bourdieu solo es un filósofo y no un verdadero sociólogo como Boudon, que: jese sí lo es!"). Lo importante es que son textos que dependen de autores y no de procedimientos lógicos formalizados o de comunidades científicas cerradas en torno a un paradigma indiscutido y a unas reglas de investigación pautadas de manera estandarizada (normalmente dependientes de una tecnología que determina radicalmente la investigación).

${ }^{3}$ El componente salvífico de toda filosofía es variable: hay casos en que la filosofía y la reforma individual y política van de la mano (por ejemplo, el Círculo de Viena y el socialismo de la Viena Roja) y otros en que este componente es muy débil (por ejemplo, los filósofos, que pueden ser comentaristas de Otto Neurath, que se dedican a la importación académica de sus grupos de referencia). En este último caso, la política solo es comprensible para ganar el campo académico en competencia con otros grupos, pero es ininteligible en el espacio social y la esfera pública en su conjunto.
} 
- que no imposible — enrolarse en la vida intelectual. Una vez transpuesto dicho umbral se distinguían dos polos: uno, a menudo ocupado por personas de origen humilde, centrado en prácticas rituales de tipo religioso, en las que la adscripción sectaria y la celebración del culto primaban sobre el trabajo de transformación individual y sobre la producción filosófica; otro, en el que abundaban las clases pudientes, de mayor distancia respecto de las prácticas rituales, y más creativo en la modificación subjetiva y en la creación cultural. El proceso descrito por Foucault tiene un valor más general: las clases dominadas adquieren más seguridad en los entornos culturales mejor codificados y más definidos; las clases dominantes, debido a un capital cultural y a un sentido de la orientación precozmente adquirido, pueden permitirse una relación más distendida con la cultura. Sin embargo, como insiste Foucault y mostrará cualquier análisis histórico medianamente complejo, será un error convertir cierta tendencia en un tipo ideal dogmático, que presumiría, tras lo dogmático y religioso, la rigidez de las clases medias y bajas y, tras lo filosófico y creativo, las capacidades complejas de las clases cultural y económicamente privilegiadas. Los epicúreos, en su origen, tenían una composición popular, se distanciaban ostentosamente de la religión y produjeron una filosofía sofisticada. Por lo demás, la reflexión filosófica a menudo, como ya se ha dicho, estuvo unida a prácticas rituales y religiosas muy intensas.

\section{Complejidades de la producción y el consumo filosófico}

Spinoza asimilaba la filosofía a un ideal lógico pulido. Los manuales de filosofía —donde sólo se habla de ideas que se continúan, contraponen o suceden- parecen, de hecho, seguir ese modelo. Todo lo que no sea teoría puede ser abandonado en el margen de la anécdota biográfica. Las plurales recepciones e interpretaciones de los textos filosóficos, las razones diversas que pueden impulsar a reflexionar filosóficamente indican que, para comprenderlos debemos articular tres frentes de análisis que se articulan en proporciones variables: por un lado, un texto filosófico transmite un capital cultural determinado, un conjunto de consideraciones acerca del curso del mundo (o mensaje profético) y un conjunto de propuestas de modulación subjetiva de sus receptores y seguidores (lo que podría llamarse una actividad terapéutica). Como explica Martin Kusch (1995:25) - aplicando ideas de David Bloor que producen en este punto los mismos efectos que las de Pierre Bourdieu - en las teorías filosóficas se superponen diferentes juegos de lenguaje: lenguajes teóricos, políticos, estéticos, vitales, etc. El trabajo sociológico permite desenredarlos analíticamente. Se trata del mismo fenómeno que Bourdieu (1988) destacaba a propósito de Heidegger y que no resulta imprudente generalizar. El pensamiento filosófico es, en mayor o menor medida, un "pensamiento bizco", en el que, se dice una cosa sin dejar de aludir a otra por el modo de decirlo y por los signos sutiles con los que se siembra la expresión ${ }^{4}$.

\footnotetext{
${ }^{4}$ Existen ejemplos relativamente claros de este juego entre la lengua intelectual y otros lenguajes: así,
} 
Reflexionando sobre los placeres ligados a la experiencia estética, Jean-Claude Passeron (Moulin y Veyne 1996) señalaba que el arte contiene un sentido ubicuo, imposible de reducir al contexto social de creación, a los rasgos psicológicos del autor o a los efectos sensoriales. Una descripción estrecha de los múltiples sentidos de la obra de arte permite explicar en qué consiste la experiencia social de la misma. El arte produce una experiencia particular del tiempo, permite activar conocimientos acerca del trabajo del artista, anuda un pacto icónico con un receptor, genera un sentimiento de distinción cultural, gratifica —o penaliza—al receptor según su acumulación de capital cultural. Además, los artistas tienen distintos circuitos de acceso al mercado, utilizan para ello sus contactos sociales, los recursos de sus familias y sus conocimientos acerca de la rentabilidad de los distintos campos de producción. Desde mi punto de vista, este sentido ubicuo del arte se encuentra también en los múltiples juegos de lenguaje que se encabalgan en la práctica filosófica.

La sociología de la filosofía debe intentar la delimitación de los diversos ángulos de la experiencia filosófica. Experiencia que no puede reducirse a la elaboración intelectual, al placer estético producido por un texto, 0 a sus efectos formativos en la personalidad moral del productor y del receptor; tampoco, evidentemente, puede reducirse a la simple codificación intelectual de los intereses de un individuo, al efecto de distinción cultural que produce la filosofía, a su capacidad para marcar un grupo de referencia. No puede reducirse a cualquiera de tales dimensiones pero, sin considerar el conjunto de las mismas, tampoco se comprende. Al analizarlas como conjunto, la sociología de la filosofía puede realizar así una fenomenología de la experiencia filosófica que, como toda buena fenomenología, revelará más capas de sentido que las que concede la visión puramente teórica de la creación intelectual en general y filosófica en particular.

Esas capas de sentido incluirán, la lista no es exhaustiva, los efectos del origen social y de la formación escolar en la escritura filosófica, los efectos producidos en una obra por la recepción de la misma, efectos derivados de la adaptación consciente o inconsciente a ciertos mercados culturales (citas elegidas, citas que se evitan, estilo de escritura...) y, sin duda, efectos de las normas burocráticas (respecto de sobre qué, cómo y dónde escribir) en la producción filosófica.

por ejemplo, cuando José Ortega y Gasset se refiere en su famoso curso de 1929 (¿Qué es la filosofía?) a los "soviets experimentales" a los que se confronta la filosofía. ( $O$ cuando, para referirse a los procesos de abstracción en La idea de principio en Leibniz los adjetiva de "comunistas".) Su auditorio y el lector comprenden fácilmente que Ortega opone lo científico, lo colectivo, estandarizado y comunista a lo filosófico, lo individual, lo creativo y lo liberal. 


\section{¿QUIÉN DIJO REDUCCIONISMO? FERTILIZACIONES MUTUAS dE LA SOCIOLOGÍA Y LA FILOSOFíA}

\section{La filosofía absorbida por la sociología}

Los útiles sociológicos continúan, como señalan Pierre Bourdieu (1997:41), Louis Pinto (1987:7) o Martin Kusch (1995:23), la exigencia de reflexividad inscrita en ciertas tradiciones filosóficas ${ }^{5}$. Y no precisamente, de las menos exigentes técnicamente. Hablando de la antropología, Merleau-Ponty (1960:139) escribía: "Lo que le interesa a la filosofía de ella, es precisamente que toma al hombre como es, en su situación efectiva de vida y conocimiento". Para la comprensión del ser propio de la filosofía, Merleau-Ponty (1960:147) insistía en eliminar la alternativa de quienes quieren reducirla a "la historia del individuo y de la sociedad y aquellos que piensan por el contrario que la conciencia filosófica tiene por principio las claves de la historia social y personal". Ambas alternativas se apoyan en una filosofía reduccionista. En el primer epígrafe de este texto discutimos la segunda (una filosofía "canónica" de la filosofía). Conviene decir algo sobre la primera alternativa, una sociología "reduccionista" de la filosofía.

Antes de analizar el "reduccionismo" sociológico, cabe indicar que este se encuentra, fundamentalmente, en la sociología de la filosofía que imaginan ciertos filósofos más que en la que practican de hecho las diferentes sociologías solventes. Es difícil —por no decir imposible - encontrar un análisis sociológico de la filosofía que considere que la filosofía es un simple encubrimiento de relaciones de poder. Sin embargo, son muchos los filósofos que argumentan como si esa fuera la característica principal de cualquier proyecto de sociología de la filosofía (Kusch 1995:18 y 2000: 30).

Evidentemente, existen análisis que relacionan de manera simplista los argumentos filosóficos con determinadas instituciones sociales o determinadas posiciones en el espacio social. Adorno (1987:20), por ejemplo, relacionaba la filosofía heideggeriana con los grupos sociales que realizaban un trabajo intelectual pero que padecían una situación social vulnerable. La jerga servía para afirmarse como parte de una elite a la que en el fondo no pertenecían.

Este tipo de reduccionismo sociológico parte de un supuesto: pretende incluir a la filosofía en un paradigma lógicamente más potente — representado por las ciencias sociales en general o la sociología en particular. Los problemas filosóficos, serían, sociológicamente tratados, susceptibles de superación. La jerga existencial, según Adorno, constituiría un caso de figura de una experiencia social más amplia: el de las formas simbólicas compensatorias de la pequeña burguesía en crisis. Los conceptos funcionan como marcadores de pertenencia a un grupo, a cuya conservación subordinan

\footnotetext{
${ }^{5}$ ¿Hay filosofías irreflexivas? Todas aquellas centradas en el cultivo cuasirreligioso de un autor y un canon teórico y que contemplan cualquier duda sobre su pertinencia global o sobre los intereses de los celebrantes, como un ataque a LA filosofía. Evidentemente, no es raro que los filósofos de ese tipo se parezcan más a los escoliastas (comentadores de comentadores) que a cualquier filósofo, por modesto que sea..
} 
los valores semánticos (el significado se altera en función de necesidades pragmáticas del grupo) y los desafíos que presenta la confrontación empírica (las teorías se convierten en insensibles al desmentido empírico).

Aunque la apreciación de Adorno fuera correcta para la coyuntura que describe, podría fácilmente mostrarse que los mismos argumentos teóricos pueden desempeñar papeles muy diversos según las coyunturas sociales, los estados del campo intelectual y las características de los agentes. Los conceptos sociológicos ("pequeña burguesía", "filosofía como compensación simbólica"), como ha reiterado Jean-Claude Passeron (2006), son tipos ideales que dependen de la configuración específica que estudia el autor y que nunca resulta completamente repetible. Ni todos los pequeños burgueses intelectuales y precarios de la Alemania de la época necesitaban la jerga existencial, ni esta envolvía sistemáticamente comportamientos conservadores.

\section{La sociología, fuente de la filosofía}

Más que poder reducirla a sus propios términos, la sociología, lejos de engullir la filosofía, se encuentra condenada a generarla. Como Randall Collins (2000:619-620, 879-880) ha mostrado, la ciencia social produce sus propios retornos reflexivos en los cuales se abren posibilidades intelectuales propiamente filosóficas. Los procesos de abstracción y reflexividad que caracterizan a la filosofía han sido, con mayor o menor logro, una parte del trabajo de científicos sociales empíricamente competentes. Esa necesidad de reflexionar filosóficamente nace de, al menos, dos características del trabajo sociológico.

Por una parte, no existe un paradigma sociológico que permita ver todo lo que los demás ven y además todo lo que ellos no ven. Esto impide a la sociología absorber a la filosofía. Entre otras cosas, porque la sociología en particular, y la ciencia social en general, deben buena parte de sus conflictos a la imposibilidad de establecer un terreno de debate común en torno al tratamiento, la producción de conceptos sobre, y la ubicación en narrativas de conjunto de, los objetos empíricos sobre los que trabajan. Del mismo modo que la sociología puede modificar la concepción de sí misma de la filosofía, es un hecho - debido, sin duda, a la jerarquía existente entre filosofía y sociología- que los paradigmas filosóficos animan e impulsan diversas formas de hacer sociología.

Por otra parte, cada aplicación de un paradigma sociológico debe tener en cuenta que el curso del mundo histórico no permite argumentar como si dos situaciones fueran idénticas o pudieran serlo si las controlásemos experimentalmente. Las variables que constituyen un acontecimiento en el mundo histórico son complejísimas y abigarradas y lo máximo que admite una descripción es destacar la correspondencia de ciertos aspectos y la no correspondencia de otros. Comparar exige tener en cuenta contextos diferentes. Por tanto, los conceptos sociológicos, y las operaciones de investigación que permiten, deben reformularse en cada nueva investigación. De lo contrario, el trabajo científico se degrada en una doctrina. Si la razón anterior obliga al científico social a elegir entre paradigmas - lo cual conlleva una decisión filosófica, es decir, imposible de estandarizar-, ésta obliga a trabajar creativamente el propio paradigma para confrontarlo 
con la riqueza del mundo empírico - lo que conlleva repensar los propios conceptos, el sentido que transmiten, y las operaciones de investigación necesarias en cada caso-: ese trabajo exige procesos de reflexividad, de reelaboración de las abstracciones que conforman la propia teoría, de atención minuciosa a cada coyuntura y de reflexión sobre las novedades y las permanencias. Indudablemente, por medio de ese trabajo teórico, se llega fácilmente a elaboraciones filosóficas.

En ese sentido, no es extraño que la sociología haya sido una forma de continuar, por otros medios, las vocaciones filosóficas. Passeron ha explicado cómo sus fructíferas relaciones con Bourdieu se tejieron en torno a cuestiones muy generales: las posibilidades institucionales brindadas por el Centre National de la Recherche Scientifique (CNRS) y los créditos de la Fundación Ford, la recuperación de la escuela de Durkheim y los métodos de la sociología cuantitativa pero también por la crítica historicista al positivismo característica del pensamiento anterior a la Segunda Guerra Mundial. La fascinación que la sociología ejerció sobre él y sobre Bourdieu procede de "la antigua forma de atracción de Clío": "En el fondo, solo hay dos sabores bien reconocibles de la «presa humana», el que surge de la cocina filosófica de los análisis del pensamiento y el que surge del razonamiento histórico del relato de sus actos" (Moulin y Veyne 1996:306). La sociología responde a esa fascinación mediante un uso específico de la prueba o la argumentación cuyos fundamentos filosóficos pueden muy bien detectarse en las obras de Jean-Claude Passeron o de Pierre Bourdieu. Estamos ante una modalidad de un proceso más general descrito por Randall Collins (2000:523-569). Desde 1600, la filosofía transmite buena parte de la energía emocional necesaria para el trabajo científico. Este recoge dos aspectos tradicionales de la filosofía y continúa haciéndolos funcionar: por una parte, el trabajo científico - y el sociológico, por tanto- sigue permitiendo enfrentarse de un modo específico al "enigma humano"; por otra parte, la vida cientíica, con sus guerras institucionales y sus debates intelectuales, fundamentalmente en las ciencias sociales, sigue permitiendo competir por un espacio de atención, es decir, permite reproducir las formas de vida intelectual que caracterizan a la filosofía.

Así, la filosofía, bajo ciertos usos (aquellos que se apartan de la lógica del simple comentario de autores), puede estimular el conocimiento empírico. En primer lugar, porque sin los efectos discursivos de la filosofía no se entienden múltiples realidades de nuestro mundo (desde el Estado a la psiquiatría). En segundo lugar, las ciencias sociales suponen una teoría de la acción, una epistemología y una ontología: la filosofía ayuda a hacerlas explícitas y, con ello, a revisarlas. La filosofía ayuda a reflexionar sobre qué se hace al producir ciertas afirmaciones sobre el mundo a partir de una determinada organización de las pruebas aunque para ello haya que renunciar a la utilización ornamental de la filosofía y buscar en ésta aquello que puede ayudar a los objetivos específicos de las ciencias sociales (Pinto 2007:305-307).

Pero también, hay que insistir, el trabajo empírico puede ayudar a desenmascarar la filosofía que se disfraza de ciencia. El trabajo filosófico puede definirse respecto de la ciencia de muchas maneras: se puede considerar ajeno a la ciencia o superior a ella o puede reivindicar el trabajo científico e incluso suponerse a sí mismo como ciencia. 
Existen maneras de argumentar que se presentan como ciencia social y que, en el fondo, imitan el lenguaje de la misma sin producir nada empíricamente relevante. En ese caso, estamos ante discursos de textura mixta: se adhieren a los principios del trabajo científico aunque con dos rasgos que revelan su lejanía. En primer lugar, huyen como de la peste del inevitable trabajo de protocolarización de los enunciados. En segundo lugar, su interpretación de los resultados científicos reproduce eternamente un mismo lenguaje teórico que siempre se confirma. Respecto de los datos empíricos solo saben reformularlos en una lengua - la de la sociología analítica, la de la biopolítica foucaultiana, la de la sociología de Bourdieu... no solo los malos paradigmas se prestan a ello-que reitera con un catafalco conceptual lo que ya se sabe. Son lenguajes, explica Passeron (2006:548-549), que se expanden porque pueden imitarse - con mayor dificultad (el psicoanálisis lacaniano) 0 menor (la teoría del biopoder) - y proporcionan la seguridad psicológica de pertenecer a la filiación de un autor célebre. De hecho, podría considerarse que un argumento es metafísico cuando la seguridad psicológica que proporciona procede de la referencia a una autoridad (Aristóteles, Jon Elster o Heidegger...).

¿Qué distingue entonces una interpretación empírica de una interpretación metafísica? La primera genera nuevos conocimientos empíricos - muestra cosas que no se sabían porque no se veían de otra manera- mientras que la segunda se contenta en reescribir lo que ya se sabe y en aprovecharse de la referencia empírica para introducir de matute su cantinela conceptual y promover con su manierismo expresivo una escuela determinada (Passeron 2006:603), transformando el trabajo empírico en discusión escolar o escolástica. En ese territorio, la estigmatización teórica importa más que la construcción de un dispositivo de interpretación del mundo, y la violencia verbal -a menudo unida con la más absoluta ignorantia elenchi- y la gestión tensa de los grupos en conflicto se convierten en recursos centrales dentro del debate intelectual.

\section{LA VIGILANCIA DE FRONTERAS FILOSÓFICAS: LA DIMENSIÓN HORIZONTAL DE LA FILOSOFÍA}

\section{El psicologismo y las fronteras de la filosofía}

La producción filosófica se desarrolla dentro de un conjunto de temas y formas de tratarlos. Cada agente, en función de sus recursos, tenderá a preferir unos temas a otros y a abordarlos con uno u otro sesgo. ¿Por qué ciertos temas son considerados filosóficos y otros no, y por qué las formas de tratarlos son más o menos apropiadas? Los debates al respecto muestran los conflictos acerca de las fronteras de la filosofía. Dicha cuestión se encuentra íntimamente conectada con los conflictos acerca de los recursos que se exigen a cada individuo para convertirse en un filósofo reconocido.

¿Por qué ciertos temas son considerados filosóficos y otros no? La respuesta es muy sencilla: porque ciertos individuos cualificados como filósofos - cualificación contestada por otros- los introducen dentro de un espacio de variaciones posibles constituidas provisionalmente como un canon. Dado que cada tema -no es igual que se considere 
filosófico meditar sobre el cine o sobre la termodinámica-y el modo de tratamiento exigen ciertas competencias específicas - no es igual leer el Alcibiades de Platón desde una sociología histórica de las elites griegas, que mediante consideraciones filológicas-, las disputas acerca de qué es o no filosófico y de qué modo es o no adecuado, suelen ser muy significativas para comprender las diversas configuraciones históricas de la actividad filosófica ${ }^{6}$.

Martin Kusch (1995) reconstruyó la génesis de uno de los debates que mayor fortuna ha tenido en la filosofía del siglo XIX y XX. Kusch explica cómo el debate sobre el "psicologismo" en filosofía acompañó al incremento de psicólogos experimentales que accedía a las cátedras de Filosofía en Alemania entre 1893 y 1926. Dicho acceso impulsó una hibridación de roles de filósofo y psicólogo; se desató un proceso de lucha por la definición de la profesión de filósofo. La hibridación de roles fue contestada por los adalides de un proceso de salvaguarda de la originalidad del filósofo. Semejante purificación se argumentó con diversas propuestas de orden conceptual más o menos sofisticadas. Por ejemplo, Wihelm Dilthey propone distinguir entre psicología explicativa - susceptible de tratamientos científicos estandarizados- y psicología comprensiva, cuya mirada global requiere más competencias literarias que analíticas. Husserl, por su parte, critica la psicología por su debilidad científica y le propone un remedio filosófico (su fenomenología). Como muestra Kusch, las acusaciones de psicologismo brotaban en todas direcciones, pero nadie sabe bien qué es y cualquiera puede ser acusado de ello. Las cosas de la lógica, también en la filosofía, se encuentran arrolladas por la lógica de las cosas (de diferencias institucionales y de carrera docente).

\section{Ortega y la definición del filósofo}

La polémica acerca de la valía filosófica de José Ortega y Gasset, que recorrió la filosofía española entre 1940 y 1960 , puede ser analizada desde esta doble vertiente: la del proceso de depuración de roles - las fronteras de la filosofía - y la de los recursos necesarios para ejercer el oficio de filósofo.

La victoria del bando franquista en la guerra civil otorgó a la Iglesia la posibilidad de imponer el tomismo en la formación filosófica. Las condiciones de entrada en el debate se redefinieron: bastaba con dominar una red filosófica del siglo XIII y desde ella todo cuanto se desviara de la misma. Discutir a Ortega era posible sin conocer a Dilthey, Heidegger, el neokantismo de Marburgo o la fenomenología. Las condiciones de entrada en el debate filosófico habían perdido especificidad: por utilizar una expresión común de Ortega, habían dejado de estar a la "altura de su tiempo". Por otra parte, sería fácil mostrar cómo este debate, lejos de reducirse a un efecto del totalitarismo político, moviliza un importante cuestionamiento de un doble proceso de hibridación de roles asumido por Ortega: el de la filosofía con el periodismo y el de la filosofía con las ciencias sociales.

\footnotetext{
${ }^{6}$ Véase una reconstrucción modélica de un periodo del campo filosófico español en Vázquez (2010).
} 
Por un lado, la acusación de periodista dirigida hacia Ortega estigmatiza su vinculación a públicos extraacadémicos, considerando que con ello se rebaja el nivel de la filosofía. Llamándolo filósofo mundano — por ejemplo, Marrero (1961) — se insiste en su vinculación con las modas y, por ende, en su dependencia de la valoración de públicos filosóficamente poco competentes. Por otro lado, se combate una reformulación del oficio de filósofo que Ortega propuso en la última etapa de su pensamiento (fundamentalmente en la década de 1940). Me detendré en ella porque, además de ejemplificar bien el problema de las fronteras de la filosofía, ofrece un interesante programa de sociología de la filosofía.

En su "Prólogo a Historia de la Filosofía de Émile Bréhier", Ortega considera que la historia de la filosofía se comprende fatal si sólo se leen libros de filosofía. La historia que afecta a la filosofía desborda la existencia de unas supuestas formas filosóficas perennes, es decir, no puede establecerse a priori aquello relevante para la historia del pensamiento filosófico y aquello que no lo es. Pero la historia que imagina el lector de libros de filosofía, señala Ortega, fabrica clásicos y les rinde un culto beato "anticipando en su obra perfecciones imaginarias a las que, quiérase o no, adapta los textos. Queda de ese modo la obra vetustísima comprometida a tener validez para todos los tiempos" (Ortega 2006a:140-141): "Parecería invitársenos a que juzgásemos si Parménides, Plotino o Duns Scoto "tienen razón", lo mismo que pueden o no tenerla Bergson o Husserl" (Ortega 2006a:149). El auténtico trabajo histórico no puede versar sobre las ideas; 0 , si versa sólo sobre éstas, no puede considerarse historia de la filosofía. Las ideas no se entienden "abstrayendo de cuándo y por quién fue dicha o escrita" y ese entendimiento no lo facilita, en absoluto, situar cronológicamente las doctrinas sin especificar "la estructura de la vida humana en ese siglo; más rigurosamente hablando, la de una determinada generación" (Ortega 2006a:146). El estudio de la filosofía supone la descripción de un contexto -que Ortega sabe que no se puede explicitar absolutamente-y una determinada situación vital: "La idea es una acción que el hombre realiza en vista de una determinada circunstancia y con una precisa finalidad" (Ortega 2006a:147). Reconstruir una idea filosófica equivale a dibujar, con toda la densidad posible, la coyuntura, siempre original, en la que se produjo; coyuntura que recoge la experiencia vital de un filósofo en relación con un público. La exposición de las doctrinas filosóficas típica de un manual es una simple ordenación cronológica, aclara Ortega, no "del pensamiento", sino de un "espectro", de "abreviaturas" utilizables por los filósofos, para su "privada alquimia" (Ortega 2006a:149-151).

La filosofía, insiste Ortega, es también una institución, no son sólo ideas. Esa institución la componen "los profesores de filosofía", los libros comercializados, las relaciones con el Estado, el "ondulante prestigio" de los filósofos; también los filósofos ensimismados, pero no sólo ellos. La filosofía existe como un dispositivo que responde a $-\mathrm{y}$ confirma y desarrolla - una necesidad colectiva. Por tanto, Ortega insiste en el contenido sociológico de la historia de la filosofía: "¿Es posible, cuerdamente hablando, que una disciplina titulada "historia de la filosofía" se desentienda de determinar el papel social que la filosofía ha ejercido, como si su actuación fuese algo ajeno a la realidad "filosofía"?" (Ortega 2006a:152). 
De este modo, Ortega redefine las condiciones de ejercicio del oficio de filósofo y exige, para desempeñarlo cabalmente, la adquisición de recursos de historiador y de sociólogo. La filosofía académica no era sino un ejercicio escolástico. Será el modelo que se impondrá en España tras la guerra civil con el tomismo, pero persistirá cuando éste pierda su dominio y se ejercerá con ropajes nuevos: el comentario del Aquinate será sustituido, por ejemplo, por el comentario eterno de autores tan "sistemáticos" como Foucault, Nietzsche, Benjamín, Adorno o Bataille 7 . Esto hará que muchos pensadores procedentes del círculo de Ortega o de Xavier Zubiri terminen por ubicarse fuera de la filosofía. En primer lugar, porque muchos de ellos - de acuerdo con el modelo de formación filosófica impuesto por Ortega en la Universidad Central de Madrid durante la II República española - tenían recursos científicos (en medicina, matemáticas y, sobre todo, historia y sociología). En segundo lugar, porque los insultos en "ismo" se convirtieron en anatema en los concursos de provisión de puestos en las Facultades de Filosofía y en amenaza de expulsión del campo filosófico.

El ejemplo nos muestra que la definición de qué recursos se necesitan para hacer buena filosofía depende de las propiedades sociales y culturales de los individuos que participan en los conflictos. Individuos con redes sociales amplias tienen más fácil proponer una filosofía adaptada a los no especialistas ("mundana", como la de Ortega); aquellos filósofos que son un puro producto de la institución escolar, necesitan invertir en redes sociales para captar el estado de ánimo de los públicos y, por tanto, necesitan un mayor esfuerzo para llegar a públicos. Por otra parte, en la filosofía española de los años 1950, la defensa de la pureza de la filosofía ayuda a quienes sólo poseen recursos ligados a la historia de las ideas filosóficas; aquellos que poseen otros recursos (literarios, científicos...) pueden arriesgarse con propuestas más híbridas y, dado que todos los recursos no pueden acumularse a la vez, se sienten más incómodos reducidos a la historia de la filosofía.

\footnotetext{
${ }^{7}$ José Ortega y Gasset (1965:218-220) en su importante obra póstuma La idea de principio en Leibniz y la evolución de la teoría deductiva daba una extraordinaria definición del escolasticismo, utilísima para la sociología de la filosofía: recepción de ideas y de autores sin comprender el espacio social e intelectual en el que estos pensaban, sin interrogarse por cómo se les presentaron los problemas y con qué instrumentos intentaron resolverlos. Se puede ser, por tanto, escolástico de cualquiera: de Francisco Suárez o de Bourdieu, de Tomás de Aquino o de de Félix Guattari, de Aristóteles o de Wittgenstein.
} 


\section{LAS JERARQUÍAS ENTRE LOS FILÓSOFOS: LA DIMENSIÓN VERTICAL DE LA FILOSOFÍA}

\section{Un problema "legitimista" en Randall Collins}

Al estudiar el problema de la vigilancia de fronteras, el trabajo sociológico evita uno de los problemas que plantea el monumental estudio de Randall Collins. Para delimitar los filósofos que estudia, Randall Collins actúa con la canonización producida por la historia de la filosofía. Su material de análisis procede del estudio de manuales y supone que aquellos considerados como grandes filósofos a lo largo del tiempo, lo son efectivamente. A corto plazo, explica Collins, la fama de un pensador se debe a su reputación mundana; a largo plazo, sin embargo, sobrevive si es capaz de provocar el interés de sus lectores. Sólo la segunda perspectiva puede proporcionar un juicio realista acerca de la calidad de un filósofo.

A la escala en que Collins se plantea su trabajo (la historia de la filosofía en todos los grandes complejos culturales) esta opción metódica resulta completamente justificada (¿quién imagina otra?). Pero Collins reconoce que con su método una duda asalta al lector. ¿Estudiamos a los filósofos con fama o estudiamos a aquellos verdaderamente creativos? La respuesta de Collins (2000:62) es tajante: en el fondo los pensadores pequeños merecían serlo, no eran más que epígonos o buenos escolares y repetidores de doctrinas. En éste como en otros planos, Collins tiende a buscar justificación ontológica a sus opciones metodológicas, esto es, a bendecir su método con una filosofía de la filosofía, cuando menos, insatisfactoria, por tender, imprudentemente, a legitimar los balances dominantes sobre la historia de la filosofía.

Por una parte, nada indica que muchos aspectos de los procesos de producción filosófica (nacimiento de la vocación, procesos de consagración...) sean mejor estudiados en las "grandes" figuras que en las "pequeñas". Por otra parte, no es necesario ser partidario de la filosofía (o la sociología) "de la sospecha" para cuestionar las jerarquías verticales entre los seres y los productos simbólicos o, por, lo menos, para interrogarse acerca de cómo se producen; en este caso, para contestar las clasificaciones canónicas de quién es o no filósofo y cuánto es o no de grande. Se puede ser muy grande en poder institucional y no ser reconocido por tus colegas, ser reconocido, por efectos de moda 0 porque no se sale del propio grupo de referencia; en ocasiones se escribe sin tener en cuenta públicos contemporáneos (es uno de los sentidos que cabe dar a la expresión de Ortega de que se filosofa en la isla de los filósofos muertos). Las jerarquías de los filósofos son plurales y pueden estar en conflicto.

Para ello resulta necesario pluralizar el concepto de consagración intelectual en el campo de la filosofía. La diferencia entre simple reputación y creatividad puede servir como guía de análisis pero debe declinarse de forma más precisa. Por una parte, diferenciando lo máximo posible las distintas vías de consagración intelectual y explorando sus complementariedades y sus discordancias. Por otra parte, definiendo cómo tales posibles intelectuales actúan en cada momento de una carrera intelectual. 


\section{Polos de excelencia intelectual}

En principio, pueden distinguirse tres polos de excelencia intelectual. Tales polos actúan en la trayectoria de cualquier intelectual: definirse por uno o por otro, no sólo tiene consecuencias vitales, sino también intelectuales. Por un lado, los intelectuales pretenden un lugar de reconocimiento institucional que les permita realizar su actividad. Como esos lugares se encuentran jerarquizados, la lucha por alcanzar las cotas más altas produce un cierto tipo de inversión de energías: esa inversión, si tiene exito, puede ir acompañada de reconocimiento por parte de los colegas o de creación intelectual... Pero puede no estarlo: es la maldición del cacique considerado (en secreto, debido a su poder) intelectualmente nulo y con una producción intelectual cuya vigencia no sobrevive a su poder institucional. En segundo lugar, un individuo puede perseguir el reconocimiento de sus pares, es decir, de aquéllos que en un momento específico en el campo intelectual son reconocidos como competentes. Dependiendo de si el campo intelectual y las instituciones universitarias y de investigación se encuentran sincronizados (lo que en muchas ocasiones no sucede), ese reconocimiento irá o no acompañado de ascenso institucional. Por lo demás, ese reconocimiento puede ir acompañado de un verdadero esfuerzo creador. Pero puede no estarlo: en demasiadas ocasiones el campo intelectual se encuentra dogmatizado y poco atento a todo lo que no sea el autobombo mutuo (Bourdieu 1966:872). Pierre Bourdieu (1997:104-109) ha identificado esta situación con una diferencia (de gran potencia para la sociología de los intelectuales) entre producción de ciclo corto (que responde a las expectativas establecidas... y que fenece con ellas) y producción de ciclo largo que subsiste a su momento de surgimiento y que sigue produciendo efectos incluso cuando los marcos culturales en los que se gestó desaparecen. El reconocimiento de los pares tiene su posibilidad brillante (ser reconocido por los intelectualmente consagrados) pero también su posible funesto (convertirse en mero reproductor de una escolástica autosatisfecha). Sólo en el caso de la producción de ciclo largo, cabe hablar de autonomía creadora de un intelectual. La creación modifica la percepción de los problemas intelectuales y conecta con públicos vitalmente alejados tanto en el espacio como, sobre todo, en el tiempo. Collins tiene razón al señalar que no sabemos quiénes son los filósofos importantes del siglo XX y recuerda el ejemplo del otrora minorado Aristóteles para quienes confían en la consagración a largo plazo. Los ejemplos de Frege o Peirce muestran que, en ocasiones, los grandes creadores son parias académicos (aunque no sólo).

Con estas tres dimensiones pueden captarse con más complejidad las relaciones de un filósofo con las distintas posibilidades que van apareciendo en su trayectoria. Desde aquel que acumula los tres tipos de consagración -Ortega, en el primer periodo de su carrera: después de la guerra civil el estado del campo cuestiona que sea más que un periodista; o Zubiri, antes de su abandono de la enseñanza tras la guerra civil; hasta quien, poco reconocido por sus pares y condenado a puestos institucionales marginales (alternando entre explicar filosofía en la facultad de ciencias económicas o expulsado de la universidad) genera una red de atención y de inspiración compleja y amplia, es el caso de Manuel Sacristán. Por otro lado, se encuentran todas aquellas carreras consagradas de 
simple reactualización del corpus filosófico clásico: caso, por ejemplo, de Sergio Rábade, quien asume con orgullo su condición de profesor de filosofía y no de filósofo. 0 aquellas en que la gran consagración institucional se compagina con el desdén de los pares y la ausencia de otra cosa que repetición escolástica. Según Carlos París (2006:117), cuando el filósofo tomista Ángel González Álvarez ocupó la cátedra de Metafísica que dejó vacante Ortega y Gasset, se comentaba "que entre ambos titulares de dicha Cátedra [...] había que medir la distancia con la unidad astronómica de los años luz".

El análisis del espacio de propiedades -instrumento utilizado por Paul F. Lazarsfeld (Becker 2002:271-286) - permite comprender las combinaciones posibles. La existencia o no de las mismas, evidentemente, es un problema empírico y no teórico; la explicación de por qué pueden combinarse y en qué coyunturas los diversos tipos de propiedades es un instrumento heurístico para analizar cómo se conectan las plurales dimensiones (institucionales, grupales, específicamente intelectuales) del campo filosófico con las trayectorias de los agentes. Así, por ejemplo, desde la situación soñada (combinación 1) hasta el contramodelo (combinación 8, que supone la salida del campo), se encuentran múltiples posibilidades. La combinación 2 acerca el reconocimiento de los pares y el poder institucional, sin que acontezca ninguna valía intelectual. Sin duda, es una de las pesadillas del mandarín universitario, aún más oscura en la combinación 4 donde se acompaña también del desdén intelectual de los colegas. La combinación 3 , verdaderamente rara, aúna reconocimiento institucional y creatividad intelectual con desprecio de los colegas: si se tiene en cuenta que la consagración institucional con el poder que supone, tiende a producir la creencia en el valor de quien la tiene, una coyuntura intelectual de ese tipo - posible cuando, por ejemplo, un filósofo sobrevive a su medio generacional y se encuentra en medio de la hostilidad de la generación posterior- es difícil de encontrar. Los outsiders académicos intelectualmente brillantes aparecen en la combinación número 5 , mientras que la 6 , menos rara de lo que parece a primera vista, incluye a los marginados institucionalmente rodeados - quizá por ciertas propiedades sociales que habría que delimitar- de un grupo de ensalzamiento. La siete, mito del genio desconocido, es difícil de encontrar: incluso los pensadores más marginales institucionalmente (Spinoza, por ejemplo) produjeron suficiente eco para despertar la atención de los intelectuales más cortesanos (Leibniz).

\begin{tabular}{cccc}
\hline $\begin{array}{c}\text { Número } \\
\text { de la combinación }\end{array}$ & $\begin{array}{c}\text { Consagración } \\
\text { institucional }\end{array}$ & $\begin{array}{c}\text { Consagración } \\
\text { intelectual }\end{array}$ & $\begin{array}{c}\text { Autonomía } \\
\text { creativa }\end{array}$ \\
\hline 1 & + & + & + \\
2 & + & + & - \\
3 & + & - & + \\
4 & + & - & - \\
5 & - & + & + \\
6 & - & + & - \\
7 & - & - & + \\
8 & - & - & - \\
\hline
\end{tabular}




\section{Creatividad como trabajo colectivo}

¿Cómo se llega a cada una de las posiciones de relevancia intelectual? La trayectoria de un filósofo comprende dos condiciones: la adquisición de un determinado capital cultural, y la inversión del mismo en la comunicación pública. Un tipo u otro de capital cultural y los modos de inversión del mismo determinan un mayor o menor reconocimiento, siempre que tales actividades se acompasen bien con los modelos intelectuales dominantes. En cuanto al tipo de capital cultural, existen recursos culturales que permiten o no participar en los debates centrales de una coyuntura intelectual concreta, esto es, de participar en lo que José Ortega y Gasset llamaba "el tema de nuestro tiempo". La adquisición de un capital cultural supone que se puede participar en lo que Karl Mannheim llamaba un "conjunto generacional" (Mannheim 1990:58). La transmisión permite la adquisición de unos recursos culturales compartidos por un conjunto de individuos susceptibles de entrar en debate. Pero la transmisión de ciertos contenidos culturales puede también condenar a sus receptores a la marginalidad intelectual.

Fue el caso, por ejemplo, de la filosofía española en la década de 1940. La fuerte presencia de la red tomista en la filosofía española de comienzo del régimen de Franco estaba representada por el dominico Santiago Ramírez que, en esos años, fue el héroe intelectual del sector más tradicionalista del gremio. Para Gustavo Bueno, entonces un joven filósofo español, Ramírez representaba una red filosófica preterida y el capital cultural que transmitía (abundantísimo y muy erudito) le impedía participar en la vida filosófica de su tiempo. Bueno recuerda así sus paseos con Santiago Ramírez en Salamanca. Ramírez era considerado por sus admiradores como la reencarnación intelectual de Domingo Soto y la comparación parecía acertada a Bueno, ya que en sus paseos comunes, pudo imaginarse qué fue el pensamiento en el siglo XVI: "Acaso, más exacto que decir que el Padre Ramírez fue un anacronismo, sería decir que fue una suerte de fósil viviente, algo parecido al raro molusco Neopilina del Silúrico, que todavía vive hoy, una supervivencia, sería decir que fue una reconstrucción, casi indiscernible del modelo original, aunque su "estructura tecnológica" fuera totalmente distinta (a la manera como la sinfonía de Mozart que escuchamos en el disco compacto reconstruye el original mediante procedimientos de digitalización desconocidos en el siglo XVIII)" (Bueno 1989:34).

Ortega y Gasset (2006b:390-391), muy sensible la temporalidad compleja de una coyuntura concreta, diferenciaba entre compartir un tiempo histórico (ser "contemporáneo") y participar de un modo de visión compartido (ser "coetáneo"). La posibilidad de participar o no con los coetáneos en un "conjunto generacional" que se encuentra en el centro de atención, permite objetivar una de las primeras condiciones de una carrera filosófica creativa. No se trata de que haya filosofías mejores o peores. Nadie, seriamente, puede establecer un ranking histórico de filosofías absolutamente caducas - no susceptibles de alguna actualización productiva-y otras fértiles por principio -incapaces de caer en el escolasticismo y el dogmatismo. La cuestión es que las filosofías permitan relacionarse con los centros de vanguardia en los que se reúnen los colegas y participar, a ser posible exitosamente, en los debates. De este modo, se asume que un tiempo histórico es la 
reunión de diferentes estructuras culturales. Algunas permiten el acceso al debate; otras condenan (durante ese periodo histórico) a situarse en los márgenes del mercado de bienes simbólicos. El abandono de la psicología por parte de Michel Foucault en los años 1950 (Moreno Pestaña 2006) muestra la capacidad del joven filósofo para advertir cuáles eran los productos simbólicos que le permitirían desarrollar con fortuna sus proyectos filosóficos. Foucault se arriesgaba a excluirse de las tendencias que vislumbraba entre sus coetáneos. Será el caso también -el cambio de referencias intelectuales- de muchos filósofos españoles de la misma década (1960) en la que se vieron envueltos en una carrera alocada por la europeización. El caso del sociólogo Alfonso Ortí (Moreno Pestaña 2008:37) es significativo. La referencia intelectual de Adorno se superpuso sobre otra, más primitiva, que dejó de cotizar simbólicamente al alza: la del filósofo español Xavier Zubiri. Ambas, sin embargo, producían efectos similares en la crítica al positivismo de la poderosa sociología cuantitativa que se importaba de los Estados Unidos. La segunda referencia le ubicaba en un proyecto intelectual pasado de moda; la primera le permitía entrar en la vanguardia intelectual de su tiempo.

Collins (2000) señala que sólo aquellos que entran en contacto con un grupo intelectualmente bien situado desarrollan los saberes que permiten atraer el centro de atención. Las situaciones de interacción intelectual se encuentran estratificadas: el contacto con los grupos altos es lo único que permite la elevación de la energía emocional.

La creatividad intelectual supone, pues, el acceso a ciertas "unidades de generación" 0 conjunto de individuos que comparten una de las alternativas que le presenta su "conjunto generacional". Cuanto mejor situado esté dicho conjunto mayores son las posibilidades de, por una parte, decidir qué capital cultural filosófico debe adquirirse y, por otra parte, con qué sentido invertirlo. Participar en un grupo de bajo estatus intelectual o participar en una interacción en la que uno no domina el sentido de la misma rebaja la fuerza emocional del individuo; lo contrario, la aumenta. La escasez de energía emocional acaba desconectando al individuo de los rituales de interacción importantes y bloqueando su capacidad intelectual. Las estrellas intelectuales, por el contrario, reciben la atención de las interacciones de más y mejores situaciones de encuentro entre intelectuales y, en tales situaciones, tienden a dominar la atención del conjunto. La necesidad del contacto cara a cara, subrayada por Collins, se revela con toda su fuerza. Gracias a ella, el creador adquiere conocimientos tácitos inaccesibles a distancia y se protege de la interpretación errática del sentido de las orientaciones intelectuales típicas de las recepciones a distancia (lo que Pierre Bourdieu llama "alodoxia").

\section{Conclusiones}

El saber intelectual no sólo se transmite por medio de los libros. Es algo que los procesos de análisis que defendemos ayudan a comprender con mucha mayor precisión. Tras delimitar los múltiples componentes - afectivos, cognitivos, políticos- de la escritura filosófica —que, por tanto, se comprenden mal haciendo historia de las ideas—, se insistió 
en que la buena historia de la filosofía requiere —no sólo, claro está- de la sociología. Posteriormente, se analizaron los efectos complejos de la filosofía respecto de la sociología: incentivo para la producción sociológica, pero también obstáculo escolástico cuando coloniza el trabajo empírico y lo desvía hacia la exposición y comentario de doctrinas. En tercer lugar, se insistió en comprender la filosofía situándolo en fronteras móviles respecto de otros saberes (literarios, científicos, etc.). Los defensores de hibridación de la filosofía y aquellos que defienden su pureza defienden recursos culturales diversos y formas enfrentadas de acceso a los distintos puestos institucionales e intelectuales -una presentación somera del debate alrededor de las cualidades filosóficas de Ortega en España sirvió de ejemplo-. Posteriormente, se exploraron las jerarquías verticales entre los filósofos y se presentó un modelo de análisis de las propiedades pertinentes en una trayectoria filosófica. Para finalizar, inspirándose en Randall Collins, se mostró cómo la creatividad intelectual surge de la dialéctica compleja entre un productor y un público, en suma, la inserción exitosa en una red intelectual.

\section{REFERENCIAS BibLIOGRÁFICAS}

Adorno, T. W. 1987. La ideología como lenguaje. Madrid: Taurus.

Becker, H. S. 2002. Les ficelles du métier. Comment conduire sa recherche en sciences sociales. París: La Découverte.

Bourdieu, P. 1966. "Champ intellectuel et projet créateur." Les temps modernes 246: 865-906.

Bourdieu, P. 1984. Homo academicus. París: Minuit.

Bourdieu, P. 1988. L'ontologie politique de Martin Heidegger. París: Minuit.

Bourdieu, P. 1997. Méditations pascaliennes. París: Seuil.

Bueno, G. 1989. Cuestiones cuodlibetales sobre Dios y la religión. Madrid: Mondadori.

Corominas, Jordi y Joan Albert Vicens. 2005. Xavier Zubiri. La soledad sonora. Madrid: Taurus.

Collins, R. 2004. Interaction Ritual Chains. Nueva Jersey: Princeton University Press.

Collins, R. 2005. The Sociology of Philosophies. A Global Theory of Intellectual Change. Cambridge/ Massachussetts/London: Harvard University Press.

Foucault, M. 2001. L'herméneutique du sujet. Cours au Collègue de France 1981-1982. París: GallimardSeuil. 
García-Borrón, J. C. 2004. España siglo XX. Recuerdos de un observador atento. Barcelona: Ediciones del Serbal.

González Duro, E. 1978. Psiquiatría y sociedad autoritaria: España 1939-1975. Madrid: Akal.

Kusch, M. 1995. Psychologism. A Case Study in the Sociology of Philosophical Knowledge. Londres: Routledge.

Kusch, M. "The Sociology of Philosophical Knowledge: A Case Study and a Defense". Pp. 15-38 in The Sociology of Philosophical Knowledge, edited by M. Kusch. Dordrecht/Boston/London: Kluwer Academic Publishers.

Laín Entralgo, P. 1945. Las generaciones en la historia. Madrid: Instituto de Estudios Políticos.

Mauger, G. 1990. “Postface”, Pp. 83-119 en K. Mannheim, Le problème des générations. París: Nathan.

Mannheim, K. 1990. Le problème des générations. París: Nathan.

Moreno Pestaña, J. L. 2006. Convirtiéndose en Foucault. Sociogénesis de un filósofo. Barcelona: Montesinos.

Moreno Pestaña, J. L. 2008. Filosofía y sociología en Jesús Ibáñez. Genealogía de un pensador crítico. Madrid: Siglo XXI.

Moulin, R. y P. Veyne. 1996. "Entretien avec Jean-Claude Passeron. Un itinéraire de sociologue." Revue Européenne des Sciences Sociales 103: 275-304.

Ortega y Gasset, J. 1965. La idea de principio en Leibniz y la evolución de la teoría deductiva. Pp. 63-323 en Obras completas Vol. VIII. Madrid: Alianza Editorial-Revista de Occidente.

Ortega y Gasset, J. 2006a. "Prólogo a Historia de la Filosofía de Émile Brehier" Pp. 135-174 en Obras completas. 1941-1955. Madrid: Taurus-Fundación Ortega y Gasset.

Ortega y Gasset, J. 2006b. "En torno a Galileo". Pp. 371-506 en Obras completas. 1941-1955. Madrid: Taurus-Fundación Ortega y Gasset.

París, C. 2006. Memorias sobre medio siglo. De la Contrarreforma a Internet. Barcelona: Península.

Pinto, L. 1987. Les philosophes entre le lycée et l'avant-garde. París: L'Harmattan.

Pinto, L. 2007. La vocation et le métier de philosophe. Pour une sociologie de la philosophie dans la France contemporaine. París: Seuil.

Spinoza, B. 1965. CEuvres 2. Traité Théologique-Politique. París: Flammarion.

Sacristán Luzón, M. 1984. "Sobre el lugar de la filosofía en los estudios superiores", Pp. 73-107 en Sacristán Papeles de Filosofía. Panfletos y materiales II. Barcelona: Icaria. 
Vázquez, F. 2010. La filosofía española. Herederos y pretendientes. Una lectura sociológica. Madrid: Abada.

Zubiri, X. 1981. Naturaleza, historia y Dios. Madrid: Editora Nacional.

JOSÉ LUIS MORENO PESTAÑA es profesor de Filosofía en la Universidad de Cádiz, es doctor en Filosofía (Universidad de Granada) y titular de una Habilitation à diriger des recherches en Sociología (EHESS, París). Investiga y publica sobre epistemología de las ciencias sociales, sociología de la filosofía y sociología de la enfermedad mental.

RECIBIDO: $05 / 07 / 2010$

ACEPTADO: 01/02/2011 